\title{
EL TESORO DEL INCA: ENTORNO SOCIOPOLÍTICO Y PROYECCIÓN HISTÓRICA DE UNA CREENCIA DE CONQUISTA* (GOBERnACIÓN DE TuCumán, Siglos XVI A XX)
}

\author{
Margarita Gentile Lafaille**
}

\section{Resumen}

Una de las creencias de Conquista más firmes entre la hueste española fue el relato acerca del tesoro del Inca; el mismo se inició tras el saqueo de los templos de Pachacamac y Coricancha y aseguraba que esos no eran los únicos tesoros. Fue el señuelo de las exploraciones hispanas hacia el Collasuyu. Sus sucesivas adaptaciones a época y lugar aseguraron su pervivencia hasta el siglo XX.

En este ensayo tratamos acerca de la incidencia de esta creencia durante la Conquista y Colonización del sur de Charcas; el tema trasciende su consideración y estudio por el Folklore, e interesa a la Etnohistoria porque fue parte de los sucesivos fracasos de la conservación de las fundaciones hispanas y de una guerra que duró más de cien años.

\section{Palabras clave}

Inca, Tucumán, Tahuantinsuyu, Tesoro del Inca, Huacas, Collasuyu, Folklore, Etnohistoria, Guerra de Calchaquí.

\begin{abstract}
One of the firmer beliefs of Conquest between the Spanish army was the story about the treasure of the Inca; the same began after the sacking of the temples of Pachacamac and Coricancha and assured that those were not the unique treasures. It was the decoy of the Hispanic explorations towards the Collasuyu. Their successive adaptations to time and place assured their survival until century XX.

In this essay we tried about the incidence of this belief during Conquest and Colonization of the south of Charcas; the subject extends its consideration and study by the Folklore, and interests to the Etnohistory because it was part of the successive failures of the conservation of the Hispanic foundations and a war that lasted more than one hundred years.
\end{abstract}

\section{Keywords}

Inca, Tucuman, Tahuantinsuyo, Inca Treasure, Huacas, Collasuyu, Folklore, Etnohistory, Calchaqui War.

\footnotetext{
* Llamamos "creencia de Conquista" a las historias, relatos, leyendas o cuentos que circulaban entre los habitantes de la gobernación de Tucumán durante el siglo XVI, que generaron y justificaron acciones; la del tesoro del Inca es una de ellas.

** Licenciada en Antropología Social, UNMSM. Investigadora CONICET - Museo de La Plata. Profesor titular ordinario, Instituto Universitario Nacional del Arte - Folklore.

Correo electrónico: margagentile@yahoo.com.ar
} 


\section{El TEMA Y SUS EPÍGONOS}

El oro, en sus distintas formas, fue uno de los puntos de encuentro entre españoles e indígenas durante la Conquista y Colonización de los territorios ultramarinos, con variantes de protagonistas, momentos y lugares; algunos curacas ayudaron a Francisco Pizarro a conseguir el oro de Pachacamac (c.1533) y Coricancha (c.15321537), Paullo Inca ayudó a saquear el del Collasuyu (c.1537), pero el curaca Chayhuac advertía a los españoles que sus ancestros podían perjudicarlos, a unos y otros, si se sacaban de su lugar los objetos con los que había sido enterrado su abuelo en una huaca de Trujillo (c.1550); por su parte, Juan Calchaquí (c.1564) y sus sucesores impidieron, hasta donde se pudo, que los valles andinos al sur de Charcas se convirtiesen en otro Potosí.

Si bien cada uno de los botines obtenidos por los españoles durante el siglo XVI fue en sí mismo un tesoro, en esa época ellos insistían en hablar de:

- Los tesoros espirituales, que eran los modelos de vida religiosos, como el testimonio de los mártires en los relatos recopilados en la Leyenda Dorada (Vorágine [c.1264]); o cívicos, como la madre de los Gracos, entre otros ejemplos romanos.

- Los tesoros materiales, que eran joyas, metales preciosos, muebles, telas y bienes exóticos, incluídos esclavos, según el modelo de riqueza basado en relatos de viajeros como Marco Polo (1298) y Odorico da Pordenone (1330); este tipo de tesoros se sabían ocultos, y que eran cúmulos de riquezas mal habidas, fruto de la avaricia y el robo, escondidos durante una huída, para resguardo a futuro y en beneficio propio; a veces los custodiaban dragones flamígeros y malolientes; pero si algún tesoro de esta clase era hallado por una persona de buen corazón, inmediatamente todos sus partes quedaban en condiciones de volver a circular y ser empleadss en buenas obras, de ahí que era imprescindible que el protagonista revalidara varias veces sus buenas intenciones a lo largo del relato.
La conjunción de asuntos derivados de ambos tipos, entremezclados a su vez en una sola historia dio lugar a un género literario, las novelas de caballería, que rápidamente pasaron del relato oral al libro a fines del siglo XV, con un éxito fulminante de ventas. Su influencia en el imaginario popular fue percibida también rápidamente por las autoridades españolas que trataron, inutilmente, de limitar su circulación (Cacho Blecua 1987, 2008; Riquer 2006, entre otros).

\section{ESPACIO Y TIEMPO ANDINOS}

En el Perú, tras las guerras entre almagristas y pizarristas (1540-1542), y luego de la rebelión de los encomenderos (finalizada en 1548), desde mediados del siglo XVI en adelante las autoridades españolas sacaron a los soldados mercenarios de las ciudades enviándolos a fundar poblaciones más allá de Charcas, con la posibilidad agregada de explorar las regiones del rumbo sur en pos de tesoros que, se decía, estaban sólo al alcance del valiente que se animara a buscarlos. Su existencia era indudable; Francisco César y sus compañeros, lo mismo que el portugués Alejo García (c.1520), habían dado noticias de lugares plenos de riqueza, potenciales tesoros; es decir, los avales estaban tan cercanos en el tiempo que, promediando el siglo XVI todavìa era posible conversar con testigos presenciales, o con quienes habían oido hablar del tema muy cercanamente a los hechos.

A esta calidad de relatos pertenecían el del Sol del Coricancha que había ganado por su participación en el saqueo del templo, y luego perdido jugando a las cartas, Mancio Sierra de Leguizamo (Cobo 1964 II: 157, entre otros autores); el tesoro descubierto c. 1550 en una huaca de Chan Chan (Feijoo 1763: 25-26); la estatua de oro macizo del Sol que guardaban Manco Inca y los incas rebeldes en Vilcabamba (Molina 1916: 75). El mismo Gonzalo Pizarro había encontrado en Jaquijahuana, luego de torturar y matar a varios curacas, la momia de Viracocha Inga rodeada de vajillas de oro y plata (Acosta 1954: 200); y hasta Giovanni Annello Oliva se hizo eco de que Sinchi Roca había sido enterrado en el Cusco "con el thesoro que tenia" (1998: 61). 
Otros sitios, un poco más lejos pero que igualmente guardaban riquezas, además de la jornada de los Césares, eran Lin Lin, Trapalanda, El Paititi y las Amazonas, respaldados en su existencia por conspícuos relatos (Gandía 1933; Levillier 1976, entre muchos otros autores).

A fines del siglo XVI, las ciudades de la gobernación de Tucumán se encontraban en relativa calma tras la caída de Vilcabamba (1572), la captura y muerte de los caciques Viltipoco y Teluy en Santiago del Estero (c.1594), y la regularización del comercio con los centros mineros (Argañaraz en Levillier 1919-1920 II: 512, entre otros).

Ya en el entresiglo, el peso de la evidencia produjo la mutación del relato canónico que venimos de reseñar. Se hablaba, y se buscaba, el tesoro del Inca; pero éste era otro, suplementario de los que ya se habían hallado en huacas y templos, y diverso también del que acompañaba a la momia de cada Inca.

La nueva versión traía a primer plano lo que parecía una antigua referencia a un cuantioso cargamento de oro fundido, originario de las minas que el Inca tenía en un lugar ubicado entre Chile y Tucumán. Los tejos eran portados en llamas camino a Cajamarca para pagar el rescate de Atahualpa, pero en algún punto de la ruta, también en los alrededores de alguna de las ciudades de la gobernación de Tucumán, los arrieros se enteraron que el Inca había sido muerto por Pizarro. Entonces, según las distintas versiones, enterraron el oro en un cerro, o lo hundieron en una laguna, a veces con recua y arrieros.

Para hallarlo debían confluir circunstancias muy precisas, tales como estar en el lugar del suceso en determinada fecha y hora cuando se harían visibles las señales que guiarían a los elegidos hacia la fortuna.

$*$

Además de los relatos orales, le dieron soporte a esta creencia de Conquista algunos cronistas que intercalaron noticias acerca de los tesoros incaicos. Leídas en conjunto, estas crónicas dejan la impresión de que parte de su éxito litera- rio radicaba en incluir, entre otros temas fijos, algo relativo a "tesoros". Cada uno de estos relatos recopilados tuvo una génesis prehispánica que se proyectó hacia dichos textos, de manera que su sola indexación, hoy día, daría lugar a muchas páginas por lo que nos limitaremos a señalar dos ejemplos.

Joan de Santa Cruz Pachacuti contaba que, en tiempo de Topa Inga Yupanqui, trescientos indios de las tierras bajas iban llevando al Cusco un cargamento de oro en polvo y pepitas, cuando se produjo una helada que quemó las plantas hasta la raíz; esta catástrofe fue interpretada como que se había faltado en alguna ofrenda de manera que, para contrarestar la desgracia, se enterraron muy hondo, el oro y sus cargadores, en la ladera oeste del cerro Pachatusan (Santa Cruz Pachacuti 1993: f.29r); éste era el mismo cerro de donde había salido un animal fabuloso cuando nació Amaro Topa Ynga, el hermano de Topa Ynga Yupanqui que se había dedicado a las mejoras agropecuarias durante el gobierno de Pachacutec (Gentile 2007), y esta ofrenda para recuperar el bienestar agropecuario, si existió, contenía los elementos básicos de una capacocha, aunque formada por muchachos ${ }^{3}$, no por niños.

Otro ejemplo: el jesuita Giovanni Annello Oliva contaba que con el oro que Huascar había recibido durante la ceremonia del rutuchicuy (corte de pelo), su padre Huayna Capac mandó "se forjase una cadena que llaman Uasca . . . Desta cadena pues tan preçiosa y de tan gran tesoro, le quedó al Prínçipe el renombre de Uáscar...." (Anello Oliva 1998: 81), y que cuando “... llegó la nueba de cómo los españoles abía desembarcado y saltado en Tombis, de la qual nueba todos queda atónitos. Y entonçes, por consejo del dicho Quisquis, esconde gran máquina de riqueza baxo de tierra y más dize que por horden del dicho Guascar Ynga, antes que obiera abido guerras y batallas, los escondieron una maroma de oro y tres mill cargas de oro y otras tantas o más de plata hazia en Condesuyo. Al fin todos los cumbis y ricos bestidos de oro también los escondieron, y por los yndios lo mismo." (Santa

3 La capacocha del cerro El Toro (Schobinger 1966) podría haber sido una ofrenda de este tipo, pero sin oro? 
Cruz Pachacuti 1993: f.42v). La cadena devino en maroma, y así el volumen de lo escondido avanzaba junto con el relato, siendo cada vez mayor, hasta llegar a que los indios irunas? escondieron lo que tenían de valor y, según Santa Cruz, sólo era cuestión de buscar bien, ya que no solamente los curacas poseerían tesoros.

$*$

Las protagonistas de todos estos relatos eran riquezas materiales pero, a diferencia de los argumentos de las novelas de caballería, en estos casos no era imprescindible "tener buenas partes" para hallarlas; por esta falta de virtudes, según fray Bartolomé de las Casas, todos los conquistadores y encomederos debían restituir a sus indios lo robado, y aconsejaba no absolverlos en la última confesión si actuaban en contrario (Gentile 2009ep, entre otros autores). Sin embargo, el conquistador y encomendero Lorenzo de Aldana había "hecho restitución" a sus indios (Calancha 1974-1981 III: 1142), no obstante lo cual se creía que en algún lugar del altiplano estaba un tesoro dejado por él (Wachtel 1990: 364).

Los argumentos a favor de la existencia de tesoros no tenían resquicios. La prueba de su existencia la constituían, además del oro y la plata hallados, los documentos oficiales ya que el botín de Pachacamac y Coricancha, entre otros, habían sido inventariados ante escribano (Hampe Martínez 1989), y no faltaban las noticias recibidas por los mismos conquistadores: a Francisco Maldonado le dijeron que en una cueva, en Vilcaconga, estaban las planchas de oro para chapear la casa de Huascar; a Simón Xuárez otro le dijo que detrás de la fortaleza del Cusco, en un llano había una bóveda bajo tierra con oro y plata (Pizarro 1978: 101-102), \&.

Sin embargo, Pedro Pizarro no era optimista en cuanto a encontrarlos porque los mismos indios que habían escondido los tesoros se ahorcaban por mandado de sus jefes para no tener oportunidad de descubrirlos "y por esta causa los tesoros escondidos en este rreyno (que son muchos), será milagro hallarlos." (Pizarro 1978: 104).

Pero estaba probado que al sur de Cusco había otros tesoros porque Paullo Inca había reuni- do para Diego de Almagro una buena cantidad de oro en el tambo de Tupisa, a pesar de que para esa fecha -siguiendo el hilo de esta clase de relatos- ya tendría que haberse ocultado el que iba para el pago del rescate de Atahualpa. Y, como si fuese poco, de regreso en el Cusco, de vez en cuando Paullo deslizaba la posibilidad de guiar al jefe de turno hacia un tesoro oculto en sótanos de la misma ciudad, cuya existencia fue avalada por testigos que lo habían visto (Temple [1946] 2009: cap. II).

No obstante, el paso del tiempo y la cantidad de hallazgos realizados no disminuían las posibilidades de encontrar un tesoro antiguo o explotar una veta desconocida hasta ese momento, sino que iban a favor de los buscadores; se creía, inclusos científicos y funcionarios de la corona, que los metales preciosos crecían en las entrañas de la Tierra, y que lo saqueado en templos y huacas podría reponerse en pocos años. El oidor Juan de Matienzo lo comentaba en relación a la calidad de las vetas: "Cuando se crían en peladeros, el oro es muy poco y en polvo, porque en los peladeros son muy delicadas las vetas que se crían encima de la haz de la tierra, y nunca se meten en la tierra de un estado arriba 4 , y ansí es poco lo que crían, con la lluvia y el sol." (Matienzo 1967: 190). El padre José de Acosta, bien informado en tantos temas, aseguraba que "Los metales son como plantas encubiertas en las entrañas de la tierra, y tienen alguna semejanza en el modo de producirse, ... porque de tal modo se producen en las entrañas de la tierra por virtud y eficacia del sol, y de los otros planetas, que por discurso de tiempo largo se van acrecentando, y cuasi propagando." (Acosta 1954: 88-89). Hasta un minero sostenía sin dudar que: "Lo propio juzgan muchos que sucede en este rico cerro de Potosí, y por lo menos vemos todos, que las piedras que años antes se dejaban dentro de las minas, porque no tenían plata, se sacaban después con ella, tan continua y abundantemente que no se puede atribuir sino al perpetuo engendrarse de la plata." (Alonso-Barba 1967: 32). Lo que el padre Alonso no dijo en este párrafo fue que el virrey Francisco de Toledo había llevado al Perú, cincuenta años antes, el método de la amalgama para extracción de la plata usando azogue,

4 Aproximadamente $80 \mathrm{~cm}$. 
método que él mismo describió en el Libro Segundo de su "Arte"; mediante la amalgama se recuperaron los relaves de Potosí que dieron lugar a nuevas fortunas (Lohmann Villena 1999, entre otros).

En su mayoría, los relatos acerca de tesoros y minas fabulosas ${ }^{5}$ se recogieron al sur de Charcas, región en la que no operaba la mita de huacas; es decir, en la gobernación de Tucumán no tenía razón de ser abrir monumentos indígenas, -con mano de obra local y trabajo rotativo-, a fin de extraer los tesoros contenidos en su interior porque no existían entierros de las dimensiones y la calidad de los del norte de Perú, del estilo de lo que hoy sabemos que fueron Sipán (Alva 1994) y Sicán (Shimada 1987), entre otros, de manera que en Tucumán toda esperanza de riqueza áurea, rápida y abundante se focalizaba, comenzaba, en las historias acerca de tesoros y vetas riquísimas.

\section{CONTINUIDADES Y CAMBIOS}

En sintonía con las circunstancias históricas de la gobernación de Tucumán, a partir del siglo XVIII las variedades del tesoro del Inca se trasmutaron en el que los jesuitas no habían podido llevarse cuando los expulsaron (1767). Luego, entre las guerras decimonónicas por la Independencia y las que siguieron entre los caudillos, el relato versó sobre la fortuna oculta de algún encomendero avaro a quien la muerte -generalmente por mano ajena- había sorprendido antes de enviar su oro y plata a España; luego fue el tesoro que el virrey Sobremonte enterró junto al arroyo Las Garzas para escabullirlo a los ingleses, también el de Juan Lavalle (que aún espera en algún punto de la quebrada de Humahuaca).

Infinidad de relatos conservaron su fascinación en el siglo XX; el tesoro de Hernando de Magallanes también aguarda en algún lugar del arenal sur peruano, lo mismo que el que Francis Drake

5 Las vetas se incorporaron a partir de 1545, cuando se descubrió Potosí, y en sus descubrimientos a veces tenían que ver los chinchillones (Lagidium), icomo animales de la Pachamama (Fortuny 1974:234)?, cuya presencia se consideraba indicadora (Alonso-Barba 1967: 40). dejó señalado con el geoglifo conocido como "candelabro de Paracas"; y como no podía faltar que se reviviera una historia de piratas, tanto en el cine como fuera de él, en el año 2005 se buscaba un tesoro que incluía piezas incaicas y anillos de obispos en el archipiélago Juan Fernández.

\section{Consecuencias de la búsqueda de TESOROS EN LA GOBERNACIÓN DE TUCUMÁN}

Volviendo a los relatos de los siglos XVI y XVII sobre el tesoro del Inca, las distintas versiones acerca de sus características y ubicación circulaban fluídamente entre la población europea y mestiza, dejando algunos rastros en la documentación colonial. Pero no eran solamente entretenidas charlas alrededor del fogón, para expresarlo de alguna manera, sino que tuvieron consecuencias graves para las frágiles fundaciones tucumanas.

Muchos de quienes habían llegado hasta allí impulsados por la esperanza de hacer fortuna, creían ciegamente en su existencia; uno de los respaldos seguramente estaba en la convicción de los relatores, pero también tenía su cuota de importancia que el tema del hallazgo de tesoros escondidos formara parte de la épica de la época, aunque luego se burlara de ella Miguel de Cervantes a través de la historia de su caballero Quijote.

Las partidas de españoles e indios amigos que se organizaban para ir tras los tesoros dejaban indefensas a las ciudades recién fundadas, cuya población -constituída por una minoría de españoles, negros esclavos e indios amigos, todos ellos incapaces de producir su propio sustento- no estaba en situación de resistir ni la indiferencia ni el asedio de sus vecinos indígenas, como efectivamente sucedió con el abandono y destrucción de las sucesivas ciudades de El Barco, y luego con la de San Miguel en 1578. Sin embargo, tras la destrucción de ésta última, el gobernador Gonzalo de Abreu organizó una expedición al año siguiente para buscar la Trapalanda (Sotelo Narváez en Torre Revello, 1941, I: 84), que, como su nombre lo indicaba, era un embuste. 
Estos ataques a las ciudades cancelaban rápidamente acuerdos morosamente conseguidos entre españoles e indios; también eran consecuencia de la misma avidez encausada por otro camino; es decir, en caso de hallarse entre los indios alguna pequeña pieza de oro, la misma bastaba para desatar en la hueste hispana la expectativa de fortunas ocultas o vetas minerales, creencia que terminaba de la peor manera con la vida de los curacas quienes, al no confesar dónde se hallaban los inexistentes tesoros eran acusados de hechiceros; en algún caso, un nombre de lugar -Hechicero Quemado- resguardó uno de esos recuerdos (Gentile 1995: nota 2).

Durante los siglos XVI y XVII reiteradamente se formaron partidas para ir en busca de tesoros. Y con esa excusa muchos recorrían la gobernación de Tucumán trayendo, de regreso, noticia de pueblos de indios, su ubicación, sistema defensivo, costumbres, recursos naturales, etcétera, datos que luego se utilizaban para organizar las malocas correspondientes; estos asaltos a los pueblos daban lugar a un tipo de resistencia por parte de los indígenas que era interpretada como "guerra", y los apresados durante la misma eran "esclavos" que se podían comprar y vender para trabajar en las chacras, casas y trajines de quienes no habían obtenido una encomienda, o la que tenían no les bastaba (Gentile 2009).

Tanto los tesoros como las minas de oro y plata, y el recuerdo idealizado de los Incas entre la población indígena de la gobernación de Tucumán fue el señuelo usado por Pedro Bohorques para hacerse reconocer oficialmente como descendiente de los Incas, afianzar su liderazgo e iniciar una rebelión que puso en peligro la presencia hispana en la región pasada la mitad del siglo XVII (Torreblanca 1696).

\section{LA SAGA DE LOS TESOROS TUCUMANOS}

Además de audacia y suerte, las búsquedas, y sus ocasionales hallazgos, estuvieron protegidos por algún santo o virgen de la devoción del narrador; pero dicha cristianización externa no impidió la manufactura de los instrumentos mágicos adecuados para hallar tesoros, entre otros las espadas con ciertos signos grabados, una hoja de las cuales se encontró en el basural español de la huaca Tres Palos, en Lima.

Afuera se quedaron consideraciones tales como que el oro de huacas y templos peruanos era el resultado de años de acumular ofrendas; tampoco importó, o pocos lo sabían, o pocos lo creían, que muchos objetos no eran de oro puro sino de cobre o plata dorada, como muchas de las piezas de Sipán y Sicán, y los vasos hallados en un escondrijo en la puna de Jujuy (Rolandi 1974), cuyo ocultamiento muy probablemente sea del tiempo del paso de Diego de Almagro por la región.

Como venimos de ver, esta creencia de Conquista -la del tesoro del Inca- permeaba las clases sociales en la gobernación de Tucumán, y a su vez se diversificaba en sus características ya que el hallazgo podía consistir en metales sin trabajar o apenas transformada la materia prima (vetas, oro en polvo, tejos), o piezas manufacturadas. Por eso, es apropiado no perder de vista, a modo de comparación, cuáles eran los temas de otras creencias vigentes en la época, que tampoco fueron patrimonio exclusivo de una clase social sino que las compartían entre todas, y que tenían un anclaje profundo en el pensamiento científico medieval, como lo afirmado acerca del crecimiento de las vetas de oro en el subsuelo, y la fe que merecían los relatos de viajeros por tierras lejanas y exóticas, como Polo y da Pordenone.

Un buen ejemplo de ésto último lo tenemos a mediados del siglo XVII, cuando el truchimán Pedro Bohorques consiguió embaucar al virrey del Perú con la -todavía vigente- leyenda de La Sal, que era una salina donde ciertos indios concurrían a cambiar oro por sal, al peso ${ }^{6}$ (Torreblanca 1696 f.5r) y, como venimos de ver, la última etapa de la centenaria guerra de Calchaquí estuvo pautada por la codicia de los gobernadores de Tucumán, a quienes Bohorques

6 Este relato tiene antecedente en los datos de Marco Polo acerca del costo de la sal en los pueblos de Asia donde dicho producto era parte importante de los ingresos del jefe local (2000: 334, 352, 361, 387). 
aseguraba, y ellos lo creían, que podía traer a los indígenas de la región a trabajar en las minas de oro y plata que ellos mismos, los indios, le descubrirían a él como "nieto del Inca".

En 1790, todavía un funcionario informaba al rey acerca de los tesoros de los Incas que se encontraban en los alrededores del Cusco (Fernández Campero en Dominguez Bordona 1935: 111); y, a fines del mismo siglo, el obispo Martínez de Compañón agregó a las láminas de su Trujillo del Perú una que retrataba al carbunco, con el hueco en la cabeza donde escondía el enorme rubí que brillaba de noche (Martínez de Compañón 1987 VI: XLVII; Gentile 2007).

De manera que no llama la atención que, en sintonía con nuevas formas de conocimiento, en 1873, impulsado por los datos obtenidos a través de una medium espiritista, Eugen Pertuiset organizara en Paris una expedición para rastrear el tesoro del Inca Atahualpa en la Tierra del Fuego, punto extremo del continente americano; y si bien el tesoro no se materializó, Pertuiset publicó en 1877 Le trésor des Incas a la Terre du Feu. Aventures et voyages dans L'Amérique du Sud (Borrero Rivera 1986: 6). No fue la única búsqueda de oro en Patagonia; menos de diez años después Julius Popper había organizado otra sociedad para lo mismo y con las mismas consecuencias negativas para los habitantes de la región, en este caso los selk `nam (onas), pero esa es otra historia (Borrero 1991); que hay oro en Patagonia quedó confirmado en febrero 2009, cuando los diarios de Buenos Aires dedicaron varias notas a contar el hundimiento en las costas australes del Polar Mist, un barco que transportaba un importante cargamento originario de unas ignotas minas de la meseta central. La impactante noticia no alcanzó, sin embargo, para revivir el recuerdo de las Reliquias, nombre con que se conocía en el siglo XVI a los sobrevivientes de un naufragio en el Estrecho (c.1539) que, se decía, vivían en casas con techos de oro y su ciudad tenía pavimento de plata, y que para encontrarlos (iy saquearlos?) se habían organizado varias expediciones desde la gobernación de Tucumán que nunca llegaron a destino.

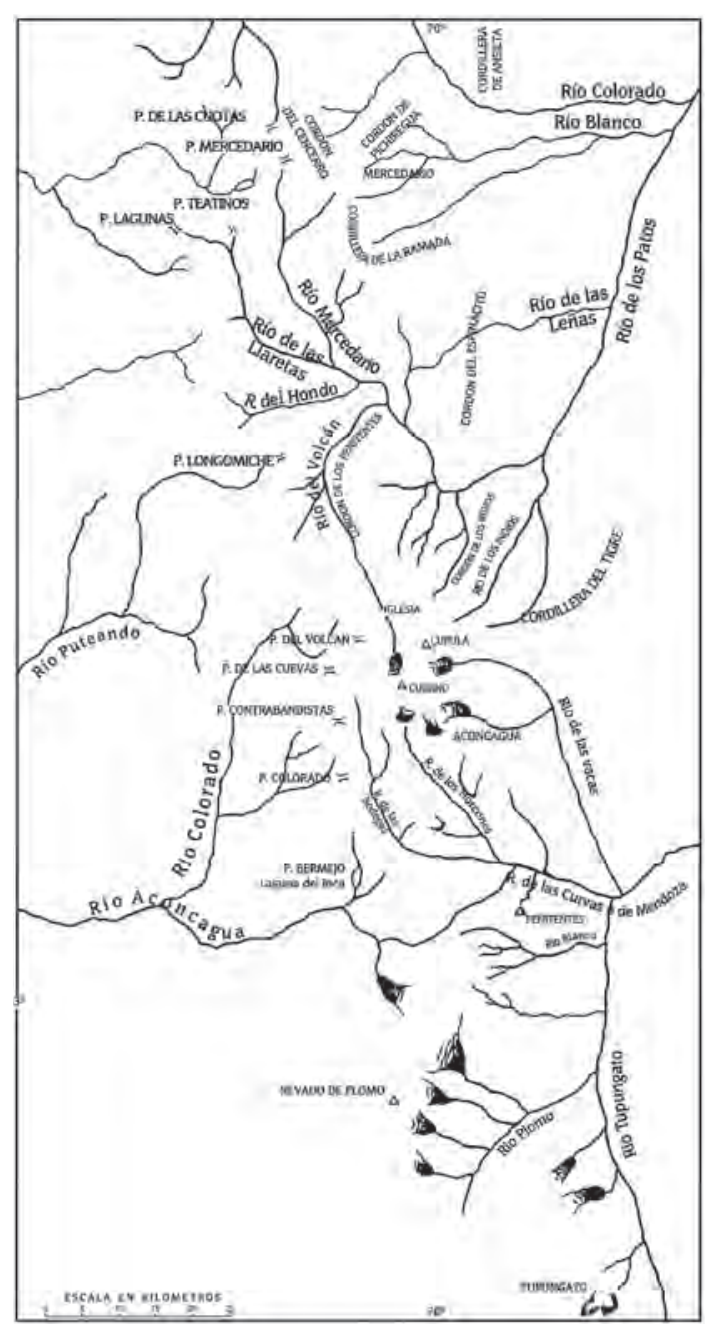

Figura 1: Ubicación de la Laguna del Inca, llamada Lacus Thesauri (laguna del tesoro) en un mapa de 1657. Se encuentra entre a mitad de camino entre las capacochas de los cerros El Plomo y Aconcagua. Según Franz Kühn, 1930: figura 31.

El Romanticismo del siglo XIX todavía produciría un cuento de la pluma de la escritora salteña Juana Manuela Gorriti titulado El tesoro de los Incas (1865). El subtítulo "leyenda histórica" hizo a medias justicia a su contenido, en parte similar a un relato ya difundido discretamente en el siglo XVI por el mismo Paullo Inca (Temple [1946] 2009: cap.II) acerca de la existencia de una ciudad subterránea bajo el Cusco español, donde se encontraban todos los tesoros incaicos. Notemos que Tiahuanaco tambíen tendría su 


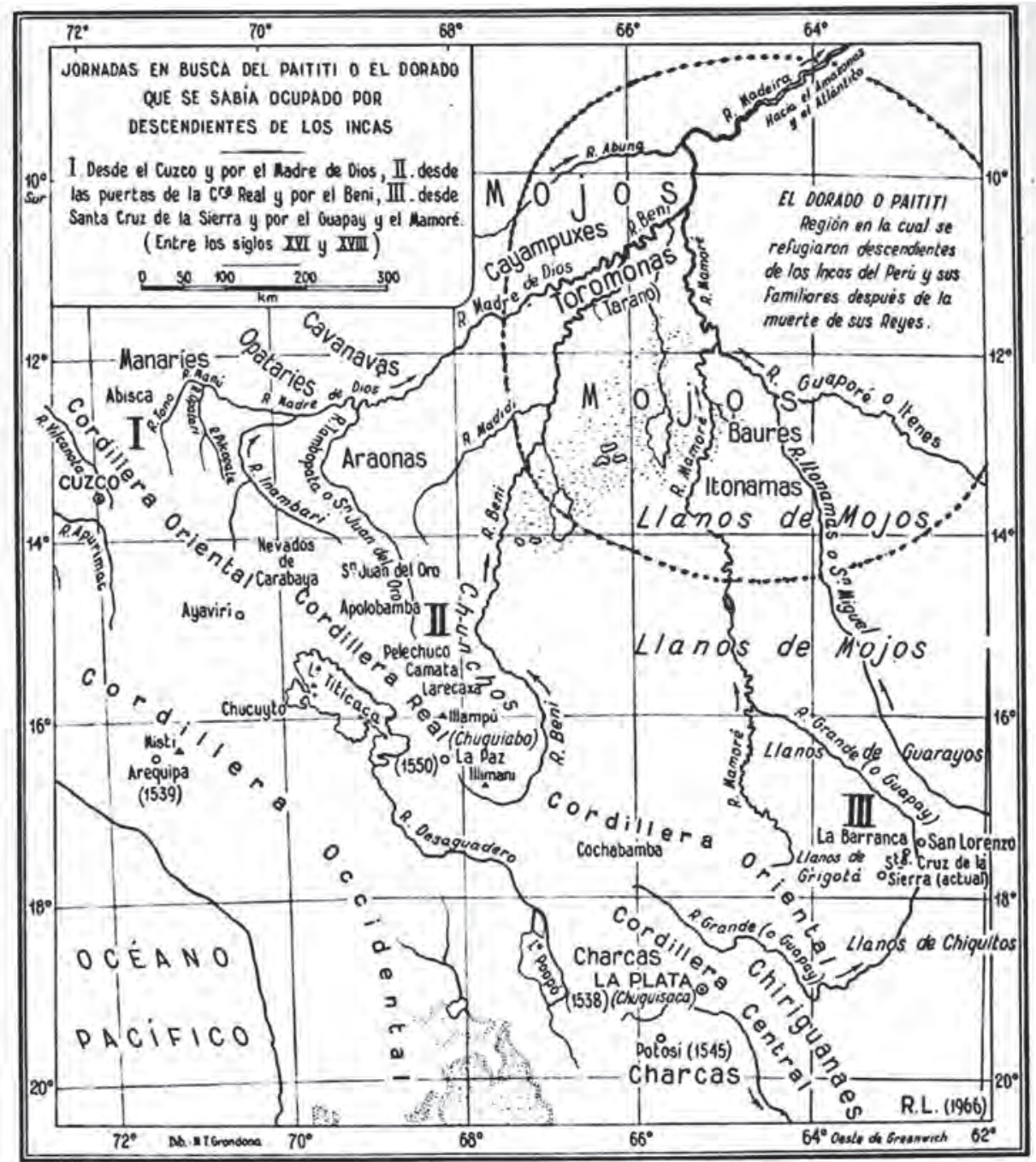

Figura 2: Mapa de la ubicación y recorrido de algunas de las jornadas realizadas entre los siglos XVI y XVIII en busca de El Dorado o Paititi. Según Levillier 1976.

réplica bajo tierra, según Manuel González de la Rosa (1910), tema que podría derivar, a su vez, de la creencia decimonónica en la existencia del rey del mundo en una sima de Asia (Ossendowski 1922: cap. XLVI y stes.)

\section{Comentarios}

El padre Bernabé Cobo decía que se llamaba coya "a las propias minas" (Cobo 1964 II: 166); de ahí que se llamara Collasuyu al sector del Tahuantinsuyu que tenía oro y plata, y que del Co- llasuyu se llevaran los tejos de oro para el pago del rescate de Atahualpa, cuyo recuerdo en esta región merece otra atención.

En términos generales, los conquistadores incaicos expandieron su poder mediante la implementación de sistemas de trabajo a nivel comunal (minga, aini) y a nivel estatal (mita) con el propósito de optimizar la producción, almacenaje y distribución a fin de alejar lo más posible la incidencia negativa de los desastres naturales, previstos mediante un sistema de registro histórico cuya forma más conocida es el quipu. Esta ges- 
tión normatizada de la mano de obra en función de la diversidad de tareas dio como resultado los excedentes con los que se atraían a la esfera de poder del Cusco a los curacas que no disponían ni de tecnología ni de mano de obra suficiente para llevar a cabo obras de infraestructura y mantenerlas, y menos aún disponían de artesanos para manufacturar objetos suntuarios.

La Historia y la Religión andinas fueron, en muchos aspectos, comunes tanto a los cusqueños como a las poblaciones que ellos incorporaban al gobierno del Cusco; en este contexto, las ofrendas tenían el valor del trabajo humano aplicado a su realización, y su acumulación era el resultado de un modo de vida estrechamente ligado con las creencias religiosas. Uno de los resultados, desde mucho antes de la fundación del Tahuantinsuyu, fue la acumulación, en los templos y huacas, de piezas realizadas según técnicas complejas y lentas, sobre todos los tipos de materia prima. Y entre ellas había también objetos en metales preciosos.

Los conquistadores españoles que llegaron al Tucumán tuvieron grandes dificultades para organizar la mano de obra indígena según sus pretensiones, porque las mismas iban en la sola dirección de la producción agropecuaria en función de la minera de Lípez y Potosí; para ellos ya era evidente que en el Tucumán, por más que dijeran buscarlos, no había ni templos ni huacas como los del Perú. Pero, su negación de la reciprocidad andina y su insistencia a instalar en esta parte de los territorios invadidos un sistema de gobierno absolutista como el que se perfilaba en Europa generaron resistencias que duraron más de cien años. En ese contexto los metales preciosos hacían la diferencia en cuanto a la calidad y alcance del poder de los gobernantes, e incentivaban la extensión de las exploraciones por su posibilidad de enriquecimiento personal.

Finalmente, como en otros aspectos de la Historia colonial, en éste -el de la creencia en la existencia del tesoro del Inca- también hubo mestizajes. Por una parte, las versiones entremezcladas de dicha creencia se mantienen latentes, por lo que es de esperar que, de vez en cuando, los medios masivos de comunicación den alguna noticia al respecto.

Por otro lado, pervivió parcialmente el método andino que había dado lugar los excedentes que maravillaron a los españoles en el siglo XVI, entre ellos la acumulación de ofrendas y la riqueza que rodeaba a los curacas. En el siglo $\mathrm{XX}$, como una manera de no gastar un dinero que no se tenía, se continuó la costumbre de aquella forma de trabajo comunal y organizado, trascendido desde las áreas rurales, conservando su nombre de "minga" y vigente entre migrantes andinos que habitan en áreas urbanas.

Y a principios del siglo XXI, acompañando el regreso a la vida natural, etcétera, se comenzó a difundir en medios no estrictamente andinos, una nueva minga que consiste en planear una acción determinada de carácter festivo y efímero; asi, se obtiene mano de obra sin tornamano ni en el cercano ni en el mediano plazo, es decir, sin retribución; expresado con otras palabras, carece de las características de la minga andina; pero permite, a quienes participan de momento, que puedan realizar su experiencia de trabajar en equipo según "antiguas costumbres".

\section{APÉNDICE DOCUMENTAL}

En lo que sigue transcribimos cuatro relatos sobre el tesoro del Inca, vigentes en el noroeste argentino a principios del siglo XX. Aún en su brevedad y estilo, estos textos atraen y sugieren. El primero de ellos reúne el tenue recuerdo del cargamento de oro destinado al pago del rescate de Atahualpa con las creencias quinientistas sobre la formación de las minas de oro y plata, y los vientos que alejan a los intrusos; la llegada a esos lugares debía hacerse chacchando hoja de coca.

En el segundo encontramos el mismo tema, pero por ser un cuento de arrieros, el relato estuvo focalizado en el ganado que transportaba el oro para el rescate; hacen su aparición, y desaparición, la Sirena y el Torito Astas de Oro, protagonistas por separado de otros relatos; la finalidad moralizante la tenemos en la expresión de la gatita blanca, quien dio la sencilla clave para poder salir del atrapante palacio del Inca. 
La urna defendida en el tercer relato, que tenía virtudes sobrenaturales, probablemente contenía una capacocha, señal de alianza con el Inca; su oráculo garantizaba la fidelidad del curaca regional, por eso conservarla equivalía a vivir en paz; el salto mortal de Ima recuerda el de Sarpay, encargada del oráculo de Apurímac, para no ser capturada por los españoles (Gentile 2007).

Finalmente, el cuarto relato está formado con retazos de otros cuentos: el de Paullo Inca buscando oro para darle a Almagro, el de Incarrí capaz de lanzarse a sí mismo con una honda, y vivir mágicamente en un nevado hasta que los, infaltables, jesuitas organizaron las fundiciones, por lo menos en el recuerdo.

\section{1, Encuesta al Magisterio}

Archivo del Instituto Nacional de Antropología y Pensamiento Latinoamericano, Buenos Aires. Soporte de registro: papel, en hojas de varios formatos y calidades; escritura a mano, con tinta; alguno a máquina.

Soporte actual para consulta: microfilm.

Transcripción de MEGL, según normas internacionales propuestas durante la Primera Reunión Interamericana de Archivos, Washigton, 1961.

\section{Provincia: Jujuy}

Caja 3, Legajo 66

Localidad: Abralaite

Escuela № 67, 1ํe envío

Director: Juan A. Sánchez

[f.7v] "Mitos. Cuando los españoles llegaron al Alto Perú bajando por lo que es hoy "Güayatayók" para internarse por la "Quebrada del Toro", cuenta Don Vicente Piñero que siendo él muy pequeño, él oía decir a sus padres que, viendo el "Rey Inca" que su gran poder se desmoronaba dijo: "Todas mis riquezas vayan al centro de mis hijos. Este Rey Inca (tal vez seria Atahualpa pues no saben su nombre) tenía por hijos á las montañas y que, al ordenar que sus riquezas fuesen depositadas al centro de ellos, se formaron asi las minas de oro y plata, razón por lo que estan persuadidos que éstos metales deben ser sagrados, y, por ésto mismo, creen que los vientos poderosos que soplan en las cumbres ellos creen que será el "Guardian de los tesoros". Asi que, cuando remontan las grandes alturas, conjuran los cerros bebiendo alcohol y masticando coca."

\section{Provincia: Tucumán}

Caja 5, legajo 200

Localidad: Puesto Los Pérez, Escuela 184

Maestras: Luedana y Luciana Lobo

[f.8r] "Cuentan que en los cerros y montañas de Tucumán existe una laguna, llamada del Tesoro. Todos esos lugares, pertenecieron al rey Inca, al aproximarse los arrieros de mulas [a] esos lugares, ven grandes cantidades de animales, entre el ganado vacuno hay un torito negro con astas de oro.

Aproximándose más a orillas de la laguna se ve una niña muy hermosa que se está peinando continuamente con un peine de oro.

Apenas nota que la ven, se zambulle y no aparece más. A las orillas de la laguna [f.9r] dice que se encuentran pepitas de oro. Se cuenta que dos camperos se extraviaron hace años ya, y salieron al mismo palacio del rey Inca. Recorrieron en dicho palacio todas las habitaciones y en todas ahí [sic por hay] riquezas de mucho valor al llegar la hora de la comida, encontraron una mesa con todo lo necesario y una sombra que los servía.

Uno de los camperos, al ver tanto oro, empezó por llenar los bolsillos. Cuando llegó la hora de salir, no se podía parar. Sin ellos saber como apareció una gatita blanca y les dijo: "Señor, si Ud. ha puesto algo en los bolsillos, saquelo, pues sino no podra salir de aquí; lo hizo asi y recien pudo levantarse."

\section{Provincia: Tucumán}

Caja 8, legajo 327 A

Localidad: Ingenio Nueva Baviera, Escuela 88 
Directora: Rosario Costas de Verges Maestras: Julia Elcheto y Teresa Costa.

Nota MEGL: en el Catálogo de la Colección de Folklore, Tucumán III: 292 figura como directora de la escuela la señorita Josefa Delia Goicochea.

[f.4r] "Leyenda - La Laguna del Oro. Existe en el norte de la República Argentina que los habitantes la llaman "Laguna del Oro". Esas regiones fueron habitadas por dependientes del Inca. El curaca que los gobernaba era rico, tenía entre sus riquezas una urna de oro, á la que le atribuían, virtudes sobrenaturales. Pensaban los indios que mientras existía entre ellos la urna tendrían tranquilidad. Todos los años en la fiesta del sol era puesta la urna en exhibición y visitada por las tribus. La esposa del curaca se llamaba Ima. Soñó una vez Ima que las hojas de los árboles caían estando verdes, pensó ella que era un sueño de mal agüero. El territorio al poco tiempo fue invadido. El curaca partió con su tropa dejando a su esposa guardadora de la urna mas habiendo llegado a su casa el gefe [sic] de los conquistadores le tuvo que entregar toda su fortuna menos la urna con la cual huyó. Habiendo sido vista por sus enemigos fue perseguida, subía cuestas empinadas y por último bajó á un valle profundo en donde se encontraba un lago, viéndose perdida se tiró á ella [sic] con su carga en el momento en que iba á ser tomada por el jefe. El lago se iluminó con una luz color de oro. El guerrero huyó temiendo la cólera de los dioses."

\section{Provincia: Tucumán}

Caja 8, Legajo 306

Localidad: La Posta, Escuela № 24

Director: Rosario Santillán.

[f.24r] "Leyendas. El Rey Ynga (narrada por Froilán Corvalán, de 81 años). El Rey Ynga vino de Catamarca perseguido por los españoles. Quiso establecerse en el Pueblo Viejo, pero lo atacaron y entonces se vino a San Ignacio. Alli estableció unas fundiciones de metales y otras en Los Hornillos. Sus enemigos lo siguieron persiguiendo: cansado el Rey se metió en una hon- da y se hondió cayendo en el Cerro Nevado, en donde dicen que vive en encanto.

Nota: Las ruinas de las citadas fundiciones de San Ignacio han sido conocidas por personas que aun viven; pero se las atribuyen a los Jesuitas, quienes tuvieron su iglesia en dicho lugar, la cual fue destruída por un incendio. Aun existen santos quemados y se dice que las campanas que existen en la iglesia de la localidad fueron fundidas en los hornos de los jesuitas."

\section{Agradecimientos}

Comprometen mi agradecimiento por compartir sus relatos sobre algunos tesoros locales Elsa y Amado Sosa, Alberto E. Sorzio y Rodolfo E. Ferrer.

\section{Bibliografía}

\section{Manuscritos}

Archivo del Instituto Nacional de Antropología y Pensamiento Latinoamericano, Buenos Aires

1921 Encuesta al Magisterio. Carpetas correspondientes a las provincias del noroeste argentino. Trascripción de M.E.Gentile L..

Biblioteca Nacional de Rio de Janeiro, Brasil

Fondo Documental Pedro de Angelis, Año 1696, I-29-2-7

"Relación histórica de los sucesos que tuvieron lugar en la misión y valle de Calchaquí, el año de 1656, en tiempo de rebelión de los indios, promovida por don Pedro Bohorques, con el título de Inga. Escrita por el padre Hernando de Torreblanca, de la Companía de Jesús y remitida al Padre Rector Lauro Núñez". Trascripción de M.E. Gentile L.

\section{Publicaciones}

Acosta, José de

[1590] 1954 De procuranda indorum salute o la predicación del Evangelio en las Indias. 
En Biblioteca de Autores Españoles, Tomo LXXIII: 389-608. Ediciones Atlas. Madrid.

Alonso-Barba, Alvaro

[1637] 1967 Arte de los metales. Seguido de notas y suplementos al libro por un antiguo minero. Juicios y comentarios. Editorial Potosí. Potosí.

Alva, Walter

1994 Sipán. Backus y Johnston. Lima.

Álvarez, Francisco

2005 "Crece el misterio sobre el millonario tesoro chileno". Diario La Nación, Buenos Aires, 29-09-2005.

Annello Oliva, Giovanni

[1631] 1998 Historia del reino y las provincias del Perú y vidas de los varones insignes de la Compañia de Jesús. Fondo Editorial Pontificia Universidad Católica del Perú. Lima.

Argañaraz, Francisco de

1596 "Información de los méritos y servicios hechos a Su Majestad por Francisco de Argañaraz, en la conquista de las provincias de Tucumán y fundación de pueblos, en especial el de Jujuy". En Levillier 1919-1920 II: 512.

Borrero, Luis A.

1991 Los selk 'nam (onas). Evolución cultural en la Isla Grande de Tierra del Fuego. Búsqueda - Yuchán. Buenos Aires.

Borrero Rivera, José S.

1986 “Tesoro inca en la Tierra del Fuego?" Diario El Tiempo, Azul, provincia de Buenos Aires. Domingo 23-11-1986, página 6.

Cacho Blecua, Juan Manuel

[1987] 2008 Introducción a "Garci Rodríguez de Montalvo, Amadís de Gaula": 17. 218. Ediciones Cátedra. Madrid.

Calancha, Antonio de la

[1638] 1974-1981 Coronica Moralizada del Orden de San Agustín en el Perú. 6 Tomos,
Ignacio Prado Pastor, editor. Lima.

Ceres, Hernán

1968 "Scardulla y el tesoro de Sobre Monte". En Todo es Historia 19: 24-31. Buenos Aires.

Cobo, Bernabé

[1653] 1964 Historia del Nuevo Mundo. 2 tomos. Ediciones Atlas. Madrid.

Feijoo, Miguel de

1763 Relación descriptiva de la ciudad y provincia de Truxillo del Perú. < http://books.google.com.ar/books $>$

Fernández Campero, Manuel

1790 "3. Representación del Coronel D. Manuel Fernández Campero a S.M. sobre la tradición de los tesoros que los Emperadores del Perú dejaron enterrados en las inmediaciones de la ciudad del Cuzco. Año 1790. f.155." Citado en Jesús Domínguez Bordona, Manuscritos de América, Catálogo de la Biblioteca de Palacio IX: 111. Patrimonio de la República. 1935. Madrid.

Gandía, Enrique de

1933 La ciudad encantada de los Césares - Última leyenda que murió en América. Librería de A.García Santos. Buenos Aires.

Gentile, Margarita E.

1995 "Análisis de algunos nombres de lugares del Noroeste argentino a partir de su ubicación y de la historia regional prehispánica y colonial”. Tawantinsuyu 1: 46-54. Universidad Nacional de Australia. Canberra.

2007 "Un relato histórico incaico y su metáfora gráfica”. Espéculo. Revista de estudios literarios. № 36 julio-octubre Año XII. Universidad de Complutense de Madrid. Facultad de Ciencias de la Información. <http://www.ucm.es/info/ especulo/numero36/relainca.html>

2009 "Tipos de maloca en la gobernación de Tucumán y su entorno, entre el siglo XVI y principios del XVII". Libro 
Homenaje a Alejandro Málaga Medina: 105-119. Academia Peruana de Historia Eclesiástica y Universidad Nacional San Agustín. Arequipa.

2009 "Formas de restitución a los indios en la gobernación de Tucumán (siglo XVII)". Ponencia en el Coloquio Del Tawantinsuyo a la Historia del Perú, 11 al 13 de noviembre. PUCP.

Gonzáles de la Rosa, Manuel

1910 "Les deux Tiahuanaco, leurs problémes et leur solution". XVI Congreso Internacional de Americanistas: 405-428. Wien.

Gorriti, Juana Manuela

[1865] 1907 "El tesoro de los Incas. Leyenda histórica". En: Sueños y realidades II: 87-128. Biblioteca de "La Nación". Buenos Aires. <http://books.google. com.ar/books $>$

Hampe Martínez, Teodoro

1989 Don Pedro de La Gasca: su obra política en España y América. PUCP, Fondo Editorial. Lima.

Kühn, Franz

1930 Geografía de la Argentina. Editorial Labor. Barcelona-Buenos Aires.

Levillier, Roberto

1919-1920 Gobernación del Tucumán - Probanzas de méritos y servicios de los conquistadores. 2 tomos. Sucesores de Rivadeneira. Madrid.

1976 El Paititi, el Dorado y las amazonas. Emecé. Buenos Aires.

Lohmann Villena, Guillermo

[1949] 1999 Las minas de Huancavelica en los siglos XVI y XVII. Pontificia Universidad Católica del Perú. Lima.

Martínez De Compañón, Baltasar J.

[1786-1790] 1987 Truxillo del Perú. Instituto de Cooperación Iberoamericana. Madrid.

Matienzo, Juan de

[1567] 1967 Gobierno del Perú. Instituto Francés de Estudios Andinos. Lima.
Molina, Cristóbal de, "del Cuzco"

[1575] 1916 Relación de las fábulas y ritos de los incas. Colección de Libros y Documentos referentes a la Historia del Perú. Lima.

Ossendowski, Ferdinand

1922 Beasts, Men and Gods. E. P. Dutton \& Company. New York.

Pizarro, Pedro

[1571] 1978 Relación del descubrimiento y conquista del Perú. Pontificia Universidad Católica del Perú. Lima,

Polo, Marco

[1298] 2000 Libro de las Maravillas. Suma de letras. Madrid.

Pordenone, Odorico da

[1330] 1987 Relación de viaje. Editorial Biblos. Buenos Aires.

Riquer, Martín de

2006 Introducción a "Joanot Martorell, Tirante el Blanco": VII-XC. Planeta. Barcelona.

Rolandi de Perrot, Diana S.

1974 "Un hallazgo de objetos metálicos en el área del río Doncellas (provincia de Jujuy)". Relaciones de la Sociedad Argentina de Antropología VIII n.s.: 153-160. Buenos Aires. <http://www. saantropologia.com.ar/relacionescoleccion/Relacionespdfs/RolandiPerrot. $\mathrm{pdf}>$

Santa Cruz Pachacuti Yamqui, Joan de

[1613] 1950 "Relación de antigüedades deste Reyno del Pirú". En: Tres Relaciones de Antigüedades Peruanas: 205-281. Ed.Guarania. Asunción del Paraguay.

[1613] 1993 Relación de antiguedades deste reyno del Piru. Instituto Francés de Estudios Andinos y Centro de Estudios Regionales Andinos "Bartolomé de Las Casas". Lima - Cusco.

Schobinger, Juan, y otros

1966 "La 'momia' del cerro El Toro". Suplemento al tomo XXI de los Anales de Arqueología y Etnología. Mendoza. 
Shimada, Izumi

1987 "Aspectos tecnológicos y productivos de la metalurgia de Sicán, costa norte del Perú". Gaceta Arqueológica Andina 13: 15-21. Lima.

Sotelo Narváez, Pedro

[1582] Relación de Pedro Sotelo Narbaez, dirigida al presidente de la Real Audiencia de Charcas, licenciado Juan López de Cepeda, en la que se describen las ciudades que se hallaban pobladas en el distrito de la gobernación del Tucumán, hace referencia al número de vecinos e indios que habitaban en la jurisdicción de cada una de ellas; costumbres, lenguas, ritos e idolatrías de los indígenas, producción natural e industrial. En: Levillier 1928 III: 325-332; Torre Revello 1941 I: 79-85.

Temple, Ella D.

[1946] 2009 La descendencia de Huayna Capac. Universidad Nacional Mayor de San Marcos. Lima.
Torre Revello, José (compilador)

1941 Documentos históricos y geográficos relativos a la conquista y colonización rioplatense, 4 tomos. Jacobo Peuser. Buenos Aires

Uhle, F. Max

[1903] 2003 Pachacamac. Informe de la expedición peruana William Pepper de 1896. Universidad Nacional Mayor de San Marcos. Lima.

Vorágine, Santiago de la

[c.1264] 1987 La leyenda dorada. 2 tomos. Alianza Editorial. Madrid

Wachtel, Nathan

1990 Le retour des ancêtres - Les indiens urus de Bolivie - XXe.-XVIe. siècle - Essai d'Histoire régressive. Éditions Gallimard. 